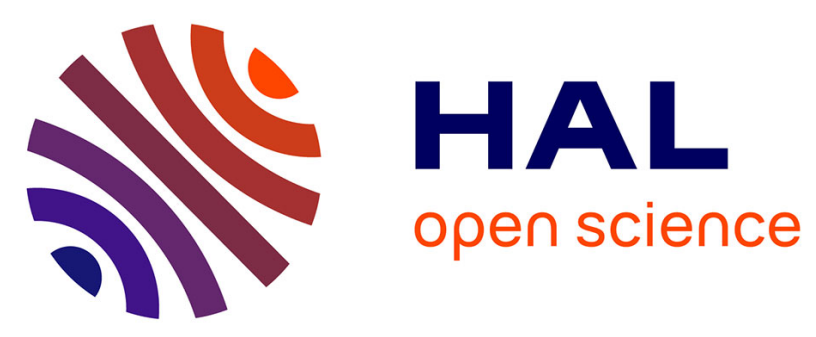

\title{
Laser based method for surface tension and density measurements for liquid refractory metals $(\mathrm{Nb}$, Ta, and W)
}

Morgan Dal, Frédéric Coste, Matthieu Schneider, Riccardo Bolis, Rémy Fabbro

\section{To cite this version:}

Morgan Dal, Frédéric Coste, Matthieu Schneider, Riccardo Bolis, Rémy Fabbro. Laser based method for surface tension and density measurements for liquid refractory metals ( $\mathrm{Nb}$, Ta, and $\mathrm{W}$ ). Journal of Laser Applications, 2019, 31 (2), pp.Article number 022604. 10.2351/1.5096138 . hal-02164822

\section{HAL Id: hal-02164822 \\ https://hal.science/hal-02164822}

Submitted on 25 Jun 2019

HAL is a multi-disciplinary open access archive for the deposit and dissemination of scientific research documents, whether they are published or not. The documents may come from teaching and research institutions in France or abroad, or from public or private research centers.
L'archive ouverte pluridisciplinaire HAL, est destinée au dépôt et à la diffusion de documents scientifiques de niveau recherche, publiés ou non, émanant des établissements d'enseignement et de recherche français ou étrangers, des laboratoires publics ou privés. 


\title{
Laser based method for surface tension and density measurements for liquid refractory metals ( $\mathrm{Nb}, \mathrm{Ta}$, and $\mathrm{W}$ )
}

\author{
Morgan Dal, ${ }^{\text {a) }}$ (D) Frédéric Coste, ${ }^{\text {b) }}$ Matthieu Schneider, ${ }^{c)}$ (D) Riccardo Bolis, ${ }^{d)}$ and Rémy Fabbro ${ }^{\text {e) }}$
}

\author{
AFFILIATIONS

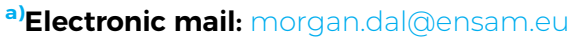

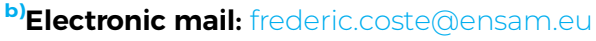 \\ ${ }^{c}$ Electronic mail: matthieu.schneider@ensam.eu \\ ${ }^{d)}$ Electronic mail: Riccardo.BOLIS@ensam.eu \\ ${ }^{\text {e)}}$ Electronic mail: remy.fabbro@gmail.com
}

Laboratoire PIMM, Arts et Métiers, CNRS, Cnam, HESAM Université 151 Bd de l'hôpital 75013 Paris, France

\begin{abstract}
The increase of process simulations in industry leads to the need of accurate knowledge of material thermal properties. As the determination of liquid metal properties is quite difficult, this article presents an experimental setup and a technique to estimate the surface tension and the density of several refractory metals $(\mathrm{Nb}, \mathrm{Ta}$, and $\mathrm{W}$ ) and their variation with the temperature. This work is based on the well known sessile droplet method applied in a controlled atmosphere (Ar) and coupled to thermal measurements. The particularity of this work is the acquisition of measurements up to high temperatures (over $3500 \mathrm{~K}$ ).
\end{abstract}

Key words: experimental setup, surface tension, density, liquid metal, tungsten, niobium, tantalum

\section{INTRODUCTION}

The determination of thermo-physical properties of liquid metals is a current challenge in the heavy industry network. In many industrial applications, the behavior of solid or liquid material has a huge effect on the final piece quality. For instance, in welding the cooling rate, which depends on material properties, can be responsible of cracking, hardening, and embrittlement. In the case of casting, the thermal expansion and the material flow, driven by surface tension, may produce shrinkage defects. Accordingly, the knowledge of metal properties could lead to enhance industrial applications.

Moreover, the numerical analysis is more and more used to improve process parameters or to observe phenomena difficult to measure. Nowadays, the physical descriptions of processes are quite well known overall, but it is still difficult to build a perfectly predictive simulation due to the high uncertainty on material properties. Up to date, literature data are consistent only at low temperature $\left(T<T_{m}\right)$ and show large discrepancies at higher temperatures.

The thermo-physical properties considered for these applications are thermal conductivity $(\lambda)$, specific heat $\left(c_{p}\right)$, density $(\rho)$, surface tension $(\gamma)$, and viscosity $(\eta)$. Their measurements need different experimental setups and here we focus on the analysis of surface tension and density measurements.

The surface tension of fluids (a liquid inside a gas or two liquids) is an interfacial energy due to the cohesion difference at the interface between the two fluids. Largely studied for common liquids, ${ }^{1}$ it can be described as the energy needed to deform this interface. In the case of metals, the surface tension is quite high. 
For instance, it is at least ten times higher than the one of water ( $\approx 2 \mathrm{~N} \mathrm{~m}^{-1}$ for iron versus $0.07 \mathrm{~N} \mathrm{~m}^{-1}$ for water). Moreover, this parameter is hugely dependent on the surface temperature and chemistry, ${ }^{2}$ producing the well known Marangoni effect.

The mastering of the surface tension and its variation is thus critical for some industrial applications. For instance, a sensitive case is the brazing where the wetting of the filler material on the substrate has a very huge impact on the ending assembly quality. Indeed, the higher the wetting, the larger the diffusion area and the better the mechanical properties. Thus, with an efficient surface tension measuring method, the properties of different filler materials could be previously quantified and selected in order to enhance wetting.

The theoretical quantification of the surface tension is quite difficult and a lot of experiments have been performed to estimate it. In the literature, the following methods can be found:

- pendant drop, ${ }^{3-5}$

- sessile drop,

- magnetic levitation, ${ }^{7,8}$

- free fall oscillating droplet, ${ }^{9}$ and

- maximum pressure bubble. ${ }^{10,11}$

In this paper, we report an application of sessile droplet method that allows one to precisely characterize the surface tension of liquid metals (niobium, tantalum, and tungsten). In future, our experimental setup will also allow one to observe contact angles for different substrates and measure dynamic viscosity.

The fundamental relation of Young-Laplace ${ }^{12}$ [Eq. (1)] describes the pressure variation (gradient at the interface) due to the surface tension $(\gamma) . \kappa$ is the local principal curvature of the interface,

$$
\Delta P=P_{L}-P_{\mathrm{ext}}=\gamma \kappa
$$

The pressures $P_{L}$ and $P_{\text {ext }}$ are, respectively, the liquid pressure and the external pressure. In the case of the sessile droplet, the main assumption is that the only external forces are linked to the gravity. Thus, considering the hydrostatic pressure and the weight of the drop, the equilibrium relation with the surface tension can be written as

$$
\gamma \kappa=\frac{m g}{\pi r_{0}^{2}}-\rho g z_{0}
$$

As summarized in Fig. 1, $m$ is the droplet mass, $g$ is the gravity amplitude, and $z_{0}$ is the height of the drop. From Eq. (2), it follows that the shape of a free sessile droplet is determined by the competition of surfaces tension and gravity. For droplet sizes smaller than the capillary length $(\sqrt{\gamma / \rho g})$, this relation is no more suitable and the surface tension can not be quantified. On the contrary, if the characteristic droplet size is larger than the capillary length, Eq. (2) is valid and the gravity significantly affects the droplet shape $\left(r_{0}\right.$ and $\left.z_{0}\right)$.

Therefore, in order to allow the use of this expression [Eq. (2)], droplets radii have been carefully chosen $(>3 \mathrm{~mm})$.

It should be noted that expression [Eq. (2)] is valid if hydrodynamic effects are negligible. Therefore, efforts have been made to minimize boundary flow effects like drop oscillations or Marangoni effect. Moreover, Eq. (2) depends on the temperature

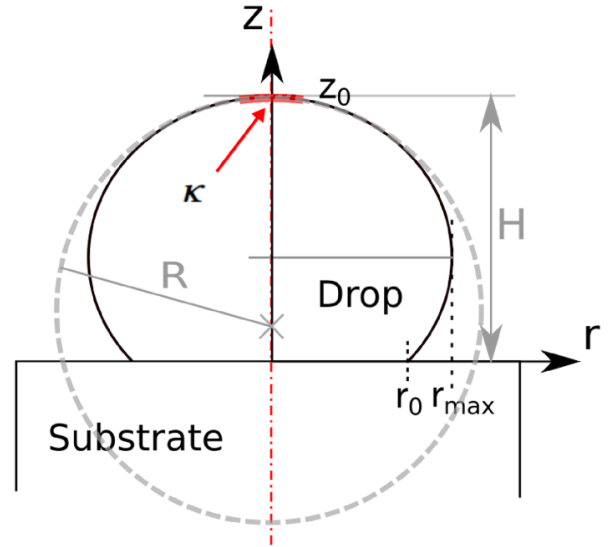

FIG. 1. Sessile drop scheme.

through density and surface tension. Therefore, the presence of a temperature gradient would significantly complicate the solution of Eq. (2). Thus, measurements have been performed with homogeneous temperature inside the drop for a measurement at a given time step.

\section{EXPERIMENTAL SETUP}

The setup shown in Fig. 2 is composed of three main components, the vacuum chamber, the droplet support, and the fast camera.

As the material properties are very sensitive to the oxygen content, the experiments have been performed in a chamber with very low content of oxygen. For satisfactory shielding conditions, the chamber has been drained (until a couple of millibars) and filled with argon gas (1 bar).

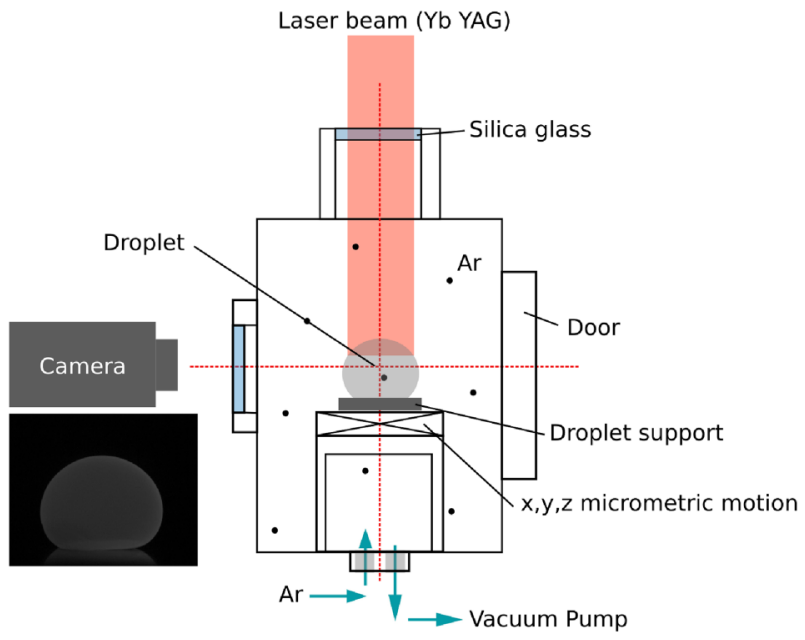

FIG. 2. Experimental setup scheme. 
TABLE I. Process parameters.

\begin{tabular}{lccc}
\hline \hline Material & Niobium & Tantalum & Tungsten \\
\hline Power (W) & $1750-2200$ & 1000 & 3000 \\
Duration (s) & $7-10$ & 3 & 10 \\
\hline \hline
\end{tabular}

The present paper deals with refractory materials; consequently, the substrate has been selected carefully. For instance, a tungsten square block has been chosen ( $5 \mathrm{~mm}$ thickness and $4 \mathrm{~cm}$ length) for niobium and tantalum samples. Tungsten is very convenient due to its high melting point and its low reactivity. A graphite disk has been used for tungsten samples. If the tungsten substrate could be reasonably supposed to not chemically affect the drop, the carbon material tends to diffuse inside the sample and disturbs the measurements.

To acquire the time evolution of the droplet shape, a fast camera (Phantom Miro Lab 310) has been used at a frequency between $500 \mathrm{~Hz}$ and $1 \mathrm{kHz}$ (depending on the fusion time duration). The acquisition window has been selected to obtain sufficient shape resolution, leading to the following scale: $8 \mu \mathrm{m}<$ $1 \mathrm{px}<15 \mu \mathrm{m}$. The camera has also been calibrated to allow temperature measurements. This technique was developed in our previous works ${ }^{13}$ in order to correlate the gray level given by a fast camera (between 800 and $900 \mathrm{~nm}$ wavelength) to the parietal temperature of liquid metals. In the present configuration, this method allows field measurements with uncertainty $\approx 5 \%$. The advantage of this technique is that it gives access to the thermal gradient due to the metallic substrate.

As shown in Fig. 2, the samples are heated by a laser. The used laser is an Yb-YAG $(1030 \mathrm{~nm})$, sufficiently absorbed by the studied materials. The laser powers and the heating duration used to melt these refractory materials are summarized in Table I.

These parameters (Table I) have been taken because they lead to the material melting without any vaporization. It should be noted that the lower energy used to melt the tantalum workpieces is due to the use of a smaller droplet size.

\section{MEASUREMENTS METHOD AND LIMITS}

\section{A. Method description}

The surface tension is deduced from Eq. (3) with several characteristic lengths that have to be measured on videos:

$$
\gamma=\frac{1}{\kappa}\left(\frac{m g}{\pi r_{0}^{2}}-\rho g z_{0}\right)
$$

The observable information needed to obtain $\gamma$ and $\rho$ are

- the curvature $\kappa$ at the droplet apex,

- the maximal height $z_{0}$ of the droplet,

- the contact radius $r_{0}$ as the contact surface $S$ is a disk,

- the sample mass $m$, and

- the volume $V$ to compute the density $\rho$.

All these quantities are extracted from fast camera measurements, with the exception of the mass $(m)$ which is measured with a high precision balance before laser irradiation (resolution $10^{-4} \mathrm{~g}$ ).
Concerning videos, a particular caution is taken about the acquisition time range. Indeed, during the laser radiation [Fig. 3(a)], a thermal (gray level) gradient can be seen below the laser beam. The presence of this thermal gradient induces a spatial gradient of the surface tension and density inhomogeneities. This prevents from the possibility to use Eq. (3) to correlate a single $\gamma$ to a given temperature.

Moreover, the surface tension gradient, induced by the thermal gradient, generates a flow via the Marangoni effect perturbing the droplet shape and creating oscillations. These disturbances further reduce the quality of the surface tension estimation.

In order to overcome this problem, only the images acquired during the sample cooling have been used. Indeed, once the laser is switched off the temperature becomes rapidly (a few milliseconds) homogeneous over the entire sample [Fig. 3(b)]. To automatically detect the laser switch off (stop) on the video, the global mean gray level $\left(\mathrm{GL}_{\text {mean }}\right)$ is computed at each time step. Figure 4 indicates the measurement interval between laser switching off and solidification of the niobium sample. Despite this interval is quite narrow, the use of fast camera allows several hundred measurements before the solidification.

A dedicated numerical tool is used to extract informations $\left(\kappa, z_{0}, r_{0}\right.$, and $\left.S\right)$.

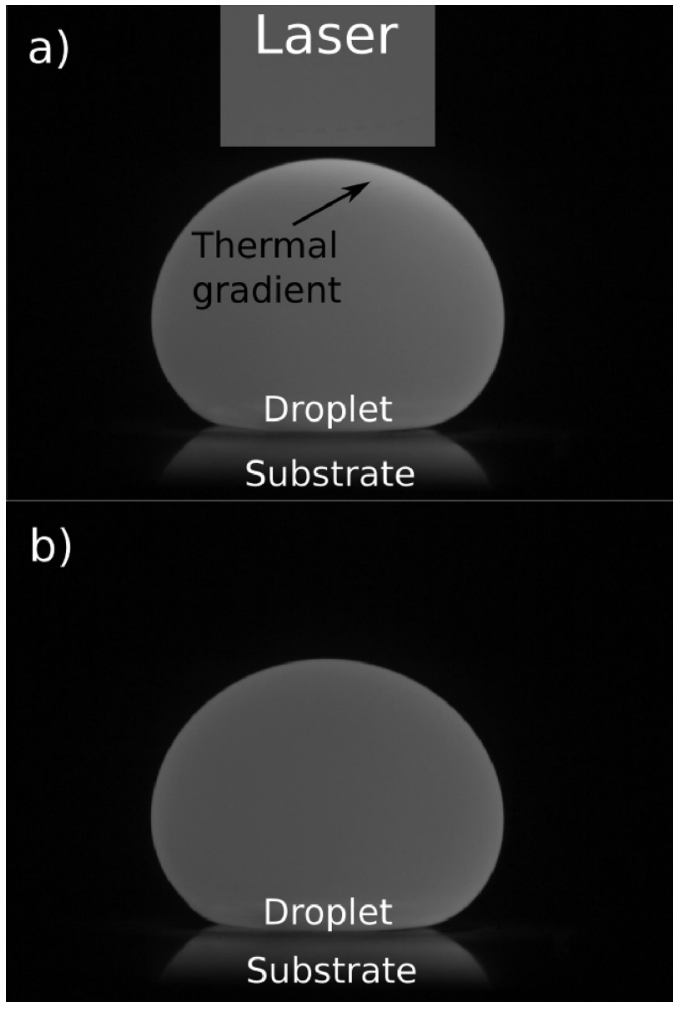

FIG. 3. Captured video, niobium example, (a) during laser radiation and (b) after laser extinction. 


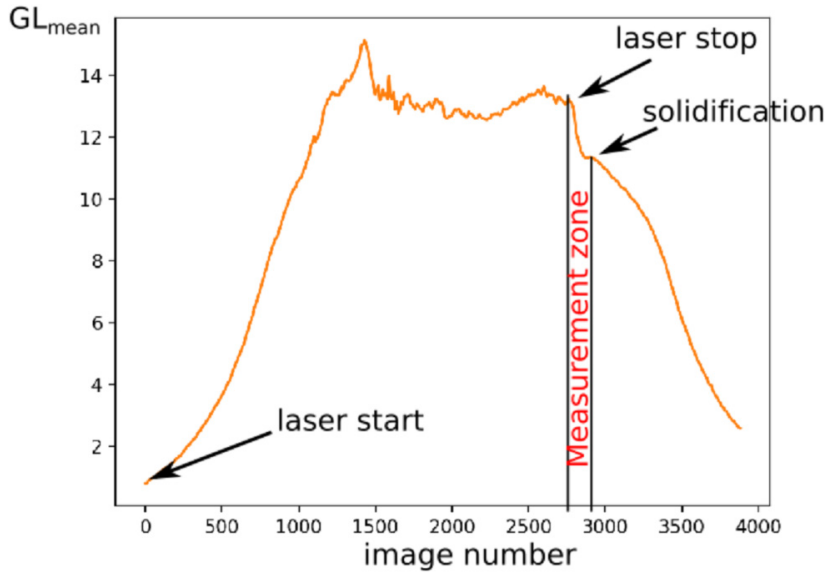

FIG. 4. Mean gray level, case of niobium.

The numerical tool has been developed with Python coupled the OpenCV 2.4 library. This tool is built through the following steps:

- Global reading and storage of the video in cache memory.

- Select the acquisition time range (gray level analysis).

- Treatment for each time step:

1. Image treatment (thresholding, centering, base line selection, reflexion removing, etc.).

2. Extract contours for each time.

3. Measure the contact radius $r_{0}$.

4. Compute the apex curvature $\kappa$.

5. Measure the droplet height $z_{0}$.

6. Compute the volume $V$ and the density $\rho$.

7. Compute the surface tension $\gamma$.

\section{B. Reproducibility and sensitive parameters}

The sessile droplet method has been largely used to measure surface tension for fluids at room temperature. In the present case, the method focuses on measurements of surface tension and its thermal variation for high temperatures (above $3000 \mathrm{~K}$ ). With our experimental design, there is no enlightening technique. The droplet can be detected by the camera only when its temperature is quite high (optical filtering between 800 and $900 \mathrm{~nm}$ ). Thus, the acquired video data are dependent on the laser energy deposition coupled to the camera and optical settings.

In order to validate the reproducibility and sensitivity to operating parameters, three experimental configurations (Table II) have been tested with niobium samples. Niobium was chosen because it is not reactive with the tungsten substrate and it is a pure material largely encountered in the literature.

The laser power and the heating duration are the usual laser process parameters. Shutter time and optical density concern the measurement diagnostics. The shutter time is a camera setting that corresponds to the acquisition time of the sample radiation by the sensor (for each image). Here, for all the cases, shutter time is a
TABLE II. Process and measurement configuration for sensitivity analysis on niobium samples.

\begin{tabular}{lrrr}
\hline \hline Case & No. 1 & No. 2 & No. 3 \\
\hline Power $(\mathrm{W})$ & 1750 & 2200 & 2200 \\
Heating duration $(\mathrm{s})$ & 7 & 10 & 10 \\
Shutter time $(\mu \mathrm{s})$ & 1 & 1 & 5 \\
Optical density & 1 & 1 & 2 \\
\hline \hline
\end{tabular}

few microseconds because of the high temperature level. Calibrated optical densities $(D=1$ and 2, Table II) are introduced in the optical path in order to reduce the sensor incident radiation $\left[D=-\log _{10}\left(I / I_{0}\right)\right]$ by, respectively, 10 and 100 . Thus, in Table II, the two last parameters have a huge effect on the luminosity of the video and affect the temperature measurement and the droplet shape detection.

It should be noted that, for niobium, the numerical tool reference parameters (threshold, baseline, etc.) were chosen from the experimental case 1 (Table II) and kept for cases 2 and 3.

For this validation step, the surface tension and the density of niobium are plotted (Figs. 5 and 6) as a function of the image number (i.e, the time). Indeed, for this validation step, the correlation with the temperature level is not yet necessary. As the energy deposition is different between case 1 and the two others, the results have to be shifted to make measurements comparable. This correction can be made because during the cooling, the temperature evolution depends only on material thermal properties and not on laser parameters. Uncertainties of results shown in Figs. 5 and 6 are summarized in Table III and illustrate that the accuracy of our technique $(<5 \%)$ is similar to the work of Paradis et al. ${ }^{14}$

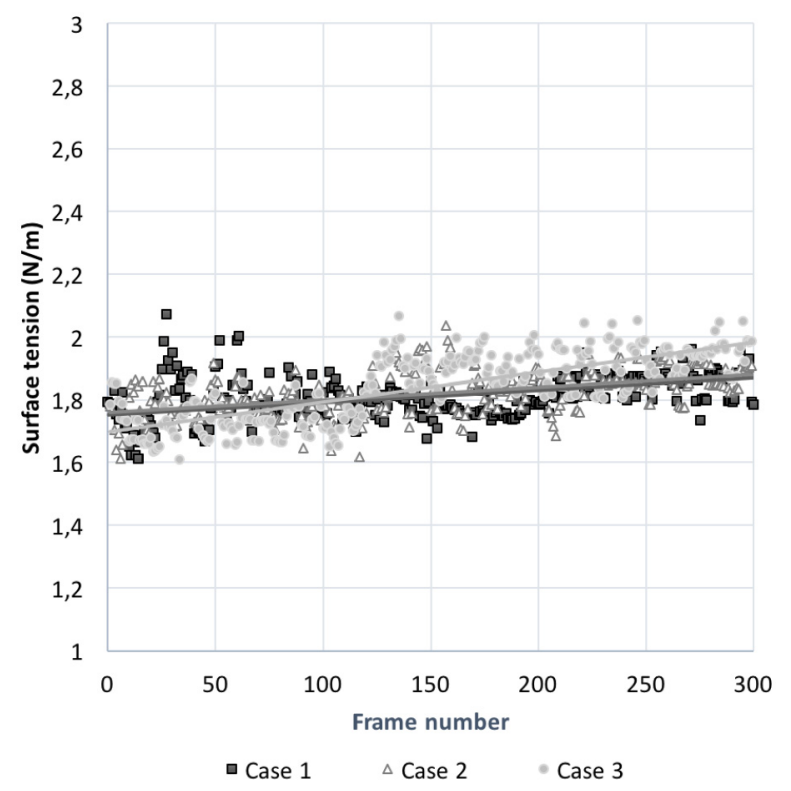

FIG. 5. Surface tension measurement for three niobium samples. 


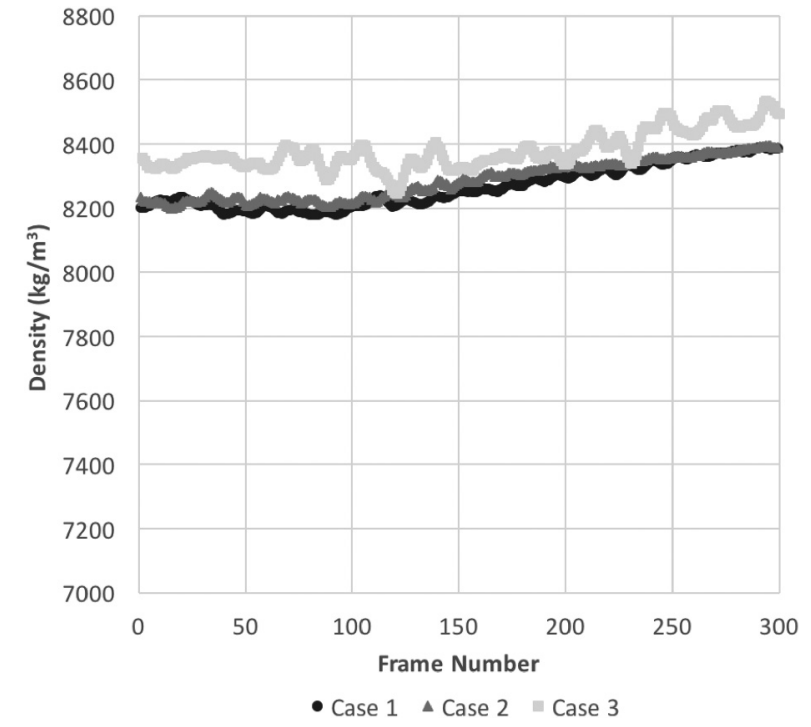

FIG. 6. Density results for three niobium samples.

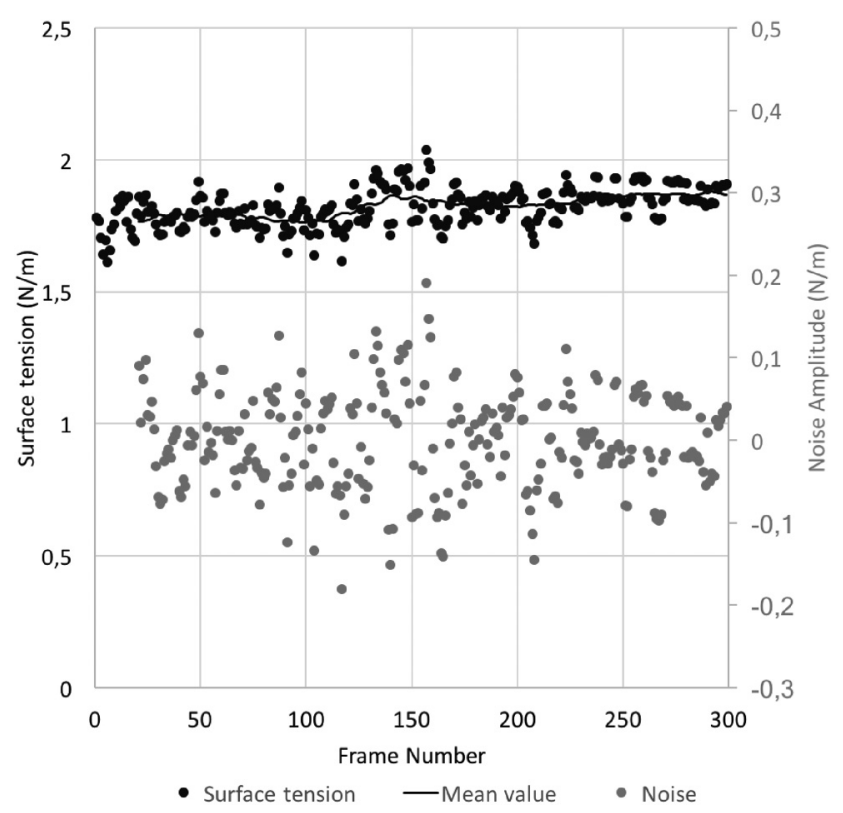

FIG. 7. Noise extraction for case 2.

settings (Table II) slightly affect the measured surface tensions and densities. This is quite clear for densities (Fig. 6) and it is evidenced by fitting curves on surface tension results (plain lines Fig. 5). For cases 1 and 2, lines are superimposed and have similar slopes whereas the third slope is much higher.

These effects of diagnostic settings on results can be explained by the thresholding performed during the picture treatment. Indeed, this method is based on contour detection. Thus, a modification of optical settings (shutter and optical density) induces a change in measured gray levels. More specifically, changes from case 1 to case 3 imply a global reduction of gray level. The binarization threshold is thus no more suitable for case 3 (too high). The measured droplet size is thus underestimated, and this leads to an overestimation of density (Fig. 6). As a consequence, the optical settings of cases 1 and 2 have been selected for the rest of the measurements.

\section{RESULTS AND DISCUSSION}

Tantalum and tungsten are two refractory materials, i.e., material with a very high melting point, 3290 and $3695 \mathrm{~K}$, respectively. ${ }^{15}$ As the process parameters (laser and diagnostics settings) are slightly different in the two cases, results are presented independently in subsections IV A and IV B.

\section{A. Tantalum}

Figure 8 shows Tantalum surface tension (black) and density (gray) obtained with our technique in comparison with literature data. $15,17-19$

Several temperatures shown in Fig. 8 are lower than the solidification point $(3290 \mathrm{~K})$. These temperatures correspond to

\begin{tabular}{llll}
\hline \hline Case & No. 1 & No. 2 & No. 3 \\
\hline SD surface tension $(\mathrm{N} / \mathrm{m})$ & 0.10 & 0.06 & 0.06 \\
SD density $\left(\mathrm{kg} \mathrm{m}^{-3}\right)$ & 8 & 7 & 8 \\
\hline \hline
\end{tabular}




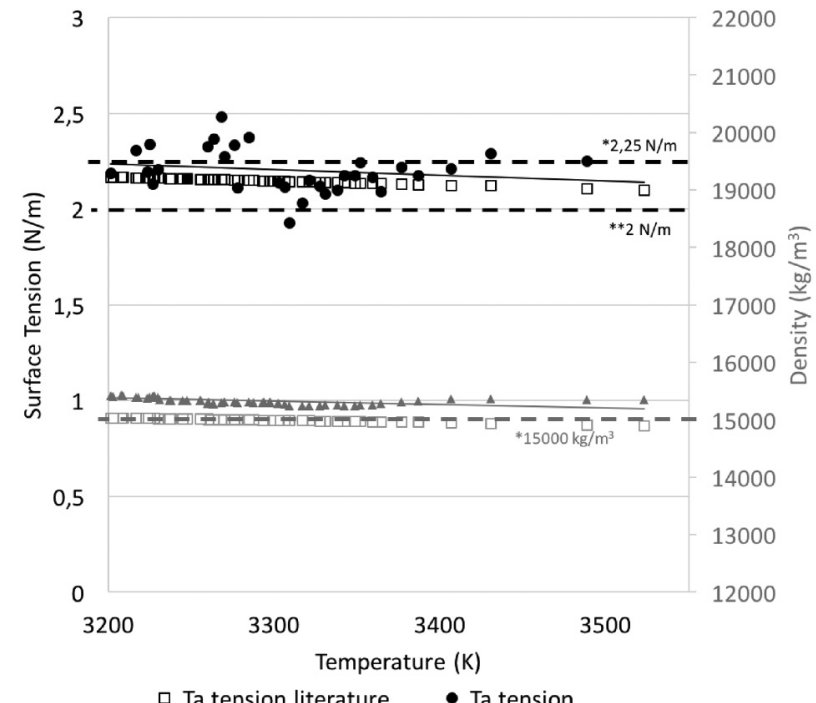

FIG. 8. Surface tension (black) and density (gray) of tantalum regarding the literature: black squares (Ref. 18), gray squares (Ref. 19), * (Ref. 15), and ** (Ref. 17).

metastable liquid states below the solidification point occurring during the cooling process (super-cooling).

Our results $(\mathrm{SD}=0.17 \mathrm{~N} / \mathrm{m})$ are in good agreement with the constant values found in the works of Aqra and Ayyad ${ }^{15}$ and Eustathopoulos et al. ${ }^{17}$ Moreover, the estimated variation of surface tension with the temperature allows the calculation of the thermocapillary coefficient $(\partial \gamma / \partial T)$ responsible of the Marangoni effect. Time dependent data coming from Paradis et al. ${ }^{18}$ are also added in Fig. 8 (black squares) and a linear fit of current measured data is plotted (black line). Assuming a linear evolution of the surface tension with the temperature [Eq. (4)], a detailed comparison is made in Table IV and a very good agreement is found between our results and the literature,

$$
\gamma(T)=\gamma_{0}+\frac{\partial \gamma}{\partial T}\left(T-T_{\text {fus }}\right)
$$

The gray part of Fig. 8 compares density measured with our technique and data reported from the literature. Similar to the surface tension, a linear fitting is made (gray line) and literature data are added (temperature variation: squares $^{19}$ and constant value: dashed line. ${ }^{15}$ Conclusions for density are similar to those concerning surface tension. The value of density at melting point

TABLE IV. Comparison between the measured surface tension and the literature.

\begin{tabular}{lcc}
\hline \hline Tantalum & Experiment & Literature $^{\mathrm{a}}$ \\
\hline$\gamma_{0}(\mathrm{~N} / \mathrm{m})$ & $2.18 \pm 0.17$ & 2.15 \\
$\partial \gamma / \partial T(\mathrm{~N} / \mathrm{m} / \mathrm{K})$ & $-2.9 \times 10^{-4}$ & $-2.1 \times 10^{-4}$ \\
\hline \hline
\end{tabular}

${ }^{\mathrm{a}}$ Reference 18 .
TABLE V. Comparison between the measured density and the literature.

\begin{tabular}{lcc}
\hline \hline Tantalum & Experiment & Literature $^{\mathrm{a}}$ \\
\hline$\rho_{0}\left(\mathrm{~kg} / \mathrm{m}^{3}\right)$ & 15415 & 15000 \\
$\partial \rho / \partial T\left(\mathrm{~kg} / \mathrm{m}^{3} / \mathrm{K}\right)$ & -0.6 & -0.4 \\
\hline \hline
\end{tabular}

${ }^{\mathrm{a}}$ Reference 18.

$(\rho 0)$ is slightly different from the literature $(<3 \%)$ and also its temperature variation $(\partial \rho / \partial T)$ seems to be coherent with the literature. ${ }^{19}$ Assuming a linear description of the density [Eq. (5)], the parameters of the law can be compared (Table V) too,

$$
\rho(T)=\rho_{0}+\frac{\partial \rho}{\partial T}\left(T-T_{\text {fus }}\right)
$$

\section{B. Tungsten}

Figure 9 is the representation of the surface tension (black part) and the density (gray part) for the tungsten sample. It should be recalled that, with this sample, the tungsten substrate cannot be used. Thus, a graphite support was used.

For both surface tension and density, results are coherent with the literature review with discrepancies higher than for the tantalum study. It can be noted that for the surface tension, literature values exibit an important scattering (from 2.3 to $2.75 \mathrm{~N} / \mathrm{m}$ ) with the lower values, near our experimental results, being the most reported. ${ }^{20}$ Data found in the literature for the thermocapillary coefficient $-2.9 \times 10^{-4} \mathrm{~N} / \mathrm{m} / \mathrm{K}$ (Ref. 15) and $-2 \times 10^{-4} \mathrm{~N} / \mathrm{m} / \mathrm{K}$ (Ref. 17) are quite close to measure [Eq. (6)].

Concerning the density, our results are slightly higher than the literature but the value stay at a satisfactory level $(<5 \%)$.

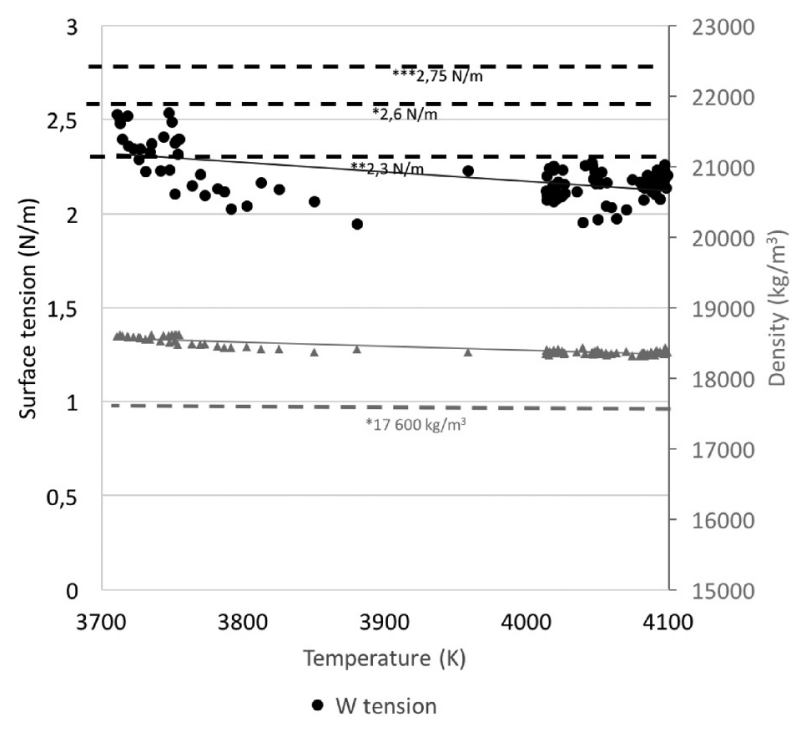

FIG. 9. Surface tension (black) and density (gray) of tungsten regarding the literature: * (Ref. 15), ${ }^{* *}$ (Ref. 17), and ${ }^{* * *}$ (Ref. 21). 
The discrepancies found in Fig. 9 can be explained by the diffusion of carbon on tungsten during the melting. Indeed, it is quite difficult to find a material able to sustain liquid tungsten due to its very high temperature. Graphite does not melt at this temperature but diffuses sensitively and affects the sample chemical composition. However, this effect does not explain these higher density values which are probably due to a measurement method disturbance. Indeed, during the diffusion of carbon in tungsten, the droplet base tends to go down inside the substrate (couple of pixels, i.e., several micrometers). Thus, the hidden part of the drop is not considered during the volume computation and, for a constant sample mass, produces a density overestimation.

The present results are thus not perfectly representative of tungsten pure material and disturbed by diffusion. The linear interpolations of surface tension and density are summarized in the following equations:

$$
\begin{aligned}
& \gamma(T)=2.34-0.0005\left(T-T_{\text {fus }}\right), \\
& \rho(T)=18600+0.59\left(T-T_{\text {fus }}\right) .
\end{aligned}
$$

\section{CONCLUSION}

To conclude, in this paper, we reported an easy-to-use laser based technique to measure surface tension and density. A particular caution has been taken concerning the laser heating that can induce high thermal levels and high thermal gradients. For this reason, measurements have been performed during the cooling. Indeed, the sessile droplet method invoves a contact between a substrate and the sample. This is very convenient experimentally, but this contact increases the thermal gradient and disturbs the measurement.

This "contact" method allows additional measurements like contact angles, but is less efficient for materials that are chemically reactive or similar to the sample (melting point).

Other perspectives and future works are about "contactless" method developments. As they are based on oscillating droplets, they lead to measure the surface tension, the density, and the viscosity.

\section{NOMENCLATURE}

$\begin{array}{ll}\mathrm{GL}_{\text {mean }} & =\text { total mean gray level } \\ g & =\text { gravity }\left(\mathrm{m} / \mathrm{s}^{2}\right) \\ m & =\text { droplet mass }(\mathrm{kg}) \\ P_{\text {ext }} & =\text { external droplet pressure }(\mathrm{Pa}) \\ P_{L} & =\text { droplet pressure }(\mathrm{m}) \\ r_{0} & =\text { droplet contact radius }(\mathrm{m}) \\ S & =\text { droplet contact area }\left(\mathrm{m}^{2}\right) \\ \mathrm{SD} & =\text { standard deviation } \\ T & =\text { temperature }(\mathrm{K}) \\ T_{m} & =\text { melting point temperature }(\mathrm{m}) \\ V & =\text { droplet volume }\left(\mathrm{m}^{3}\right) \\ z_{0} & =\text { droplet maximum height }(\mathrm{m})\end{array}$

\section{Greek}

$\gamma=$ surface tension $(\mathrm{N} / \mathrm{m})$

$\gamma_{0}=$ surface tension at melting point $(\mathrm{N} / \mathrm{m})$

$$
\begin{aligned}
\kappa & =\text { curvature }\left(\mathrm{m}^{-1}\right) \\
\rho & =\text { density }\left(\mathrm{kg} \mathrm{m}^{-3}\right) \\
\rho_{0} & =\text { density at melting point }\left(\mathrm{kg} \mathrm{m}^{-3}\right)
\end{aligned}
$$

\section{REFERENCES}

${ }^{1}$ P. G. de Gennes, F. Brochard-Wyart, and D. Quéré, Gouttes, bulles, perles et ondes (Belin, Paris, 2005).

${ }^{2}$ R. Sahoo, T. Debroy, and M. J. McNallan, "Surface tension of binary metal surface active solute systems under conditions relevant to welding metallurgy," Metall. Trans. B 19, 483-491 (1988).

${ }^{3}$ O. I. del Rio and A. W. Neumann, "Axisymmetric drop shape analysis: Computational methods for the measurement of interfacial properties from the shape and dimensions of pendant and sessile drops," J. Colloid Interface Sci. 196, 136-147 (1997).

${ }^{4}$ C. E. Stauffer, "The measurement of surface tension by the pendant drop technique,” J. Phys. Chem. 69, 1933-1938 (1965).

${ }^{5}$ J. M. Andreas, E. A. Hauser, and W. B. Tucker, "Boundary tension by pendant drops," J. Phys. Chem. 42, 1001-1019 (1938).

${ }^{6}$ W. D. Kingery and M. Humenik Jr, "Surface tension at elevated temperatures. I. Furnace and method for use of the sessile drop method; surface tension of silicon, iron and nickel,” J. Phys. Chem. 57, 359-363 (1953).

${ }^{7}$ M. Przyborowski, T. Hibiya, M. Eguchi, and I. Egry, "Surface tension measurement of molten silicon by the oscillating drop method using electromagnetic levitation," J. Cryst. Growth 151, 60-65 (1995).

${ }^{8}$ P. F. Paradis, T. Ishikawa, and S. Yoda, "Non-contact measurements of surface tension and viscosity of niobium, zirconium, and titanium using an electrostatic levitation furnace," Int. J. Thermophys. 23, 825-842 (2002).

${ }^{9}$ T. Matsumoto, H. Fujii, T. Ueda, M. Kamai, and K. Nogi, "Measurement of surface tension of molten copper using the free-fall oscillating drop method," Meas. Sci. Technol. 16, 432-437 (2005).

${ }^{10} \mathrm{~V}$. B. Fainerman, R. Miller, and P. Joos, "The measurement of dynamic surface tension by the maximum bubble pressure method," J. Colloid Interface Sci. 272, 731-739 (1994).

${ }^{11}$ A. Pamies, C. Garcia Cordovilla, and E. Louis, "The measurement of surface tension of liquid aluminium ba means of the maximum bubble pressure method: Effect of surface oxidation," Scr. Metall. 18, 869-872 (1984).

${ }^{12}$ A. W. Adamson and A. P. Gast, Physical Chemistry of Surfaces (Wiley, New York, 1997).

${ }^{13}$ M. Muller, R. Fabbro, H. El-Rabii, and K. Hirano, "Temperature measurement of laser heated metals in highly oxidizing environment using $2 \mathrm{~d}$ single-band and spectral pyrometry,” J. Laser Appl. 24(2), 22006 (2012).

${ }^{14}$ P. F. Paradis, T. Ishikawa, and N. Koike, "Non-contact measurements of the surface tension and viscosity of molybdenum using an electrostatic levitation furnace,” Int. J. Refract. Met. Hard Mater. 25, 95-100 (2007).

${ }^{15}$ F. Aqra and A. Ayyad, "Surface tension $(\gamma l v)$, surface energy $(\gamma s v)$ and crystal-melt interfacial energy ( $\gamma \mathrm{sl})$ of metals," Curr. Appl. Phys. 12, 31-35 (2012).

${ }^{16}$ S. Blairs, "Correlation between surface tension, density, and sound velocity of liquid metals,” J. Colloid Interface Sci. 302, 312-314 (2006).

${ }^{17}$ N. Eustathopoulos, B. Drevet, and E. Ricci, "Temperature co-effcient of surface tension for pure liquid metals," J. Cryst. Growth 191, 268-274 (1998).

${ }^{18}$ P. F. Paradis, T. Ishikawa, and S. Yoda, "Surface tension and viscosity of liquid and undercooled tantalum measured by a containerless method," J. Appl. Phys. 97, 053506 (2005).

${ }^{19}$ P. F. Paradis, T. Ishikawa, and S. Yoda, "Noncontact density measurements of tantalum and rhenium in the liquid and undercooled states," Appl. Phys. Lett. 83, 4047-4049 (2003)

${ }^{20} \mathrm{~A}$. Calverlay, "A determination of the surface tension of liquid tungsten by the drop-weight method,” Proc. Phys. Soc. B 70, 1040-1044 (1957).

${ }^{21}$ W. R. Tyson and W. A. Miller, "Surface free energies of solid metals: Estimation from liquid surface tension measurements,” Surf. Sci. 62, 267-276 (1977). 